\title{
MINIMISE AD (?/*IN-)FINITUM? IN DEFENSE OF WEAKLY CARTOGRAPHIC COMPUTATIONAL MODELS
}

\author{
PiOTR CEGŁOWsKI \\ Adam Mickiewicz University, Poznań \\ cpiotr@ifa.amu.edu.pl
}

\begin{abstract}
This paper provides a critical overview of the strongly derivational and non-cartographic approaches to syntax based solely on the relation between a newly selected lexical item (LI) and the so-called derivational space (the existing syntactic object) treated as the pivot of the syntactic derivation. Specifically, it is argued that, given the asymmetry requirement requisite for linearization, as stated in Kayne's (1994) Linear Correspondence Axiom (LCA) and Chomsky's (1994) Bare Phrase Structure (BPS), the abovementioned procedure is unattainable in certain strongly derivational syntactic configurations. The latter sections of the paper, while still arguing against the excessively minimized derivational space, focus on the non-cartographic Escape system proposed by Zwart (2007). It is shown that the data (comprising mostly the so-called "look-ahead"based cases) that prove problematic for Escape can be captured within a moderately (i.e. weakly) cartographic view of the left periphery in accord with Thráinsson's (1996) Limited Diversity Hypothesis.
\end{abstract}

KEYWORDS: left periphery; (non-)cartographic syntax; look-ahead; linearization; asymmetry.

\section{Technicalities first ${ }^{1}$}

\subsection{Fixed vs. flexible (FLEXIBLE) syntactic structures}

One of the main points made by Zwart (2007) concerns the distinction between "fixed" and "flexible" syntactic computations. The former are rooted in the tradition of an articulated left periphery in the spirit of Cinque (1999) and Rizzi (1997, 2004). The latter, postulated in some more recent analyses (e.g. Neeleman and van de Koot 2006; Zwart 2007), dispense with a fixed sentence format. The former are further subdivided into

\footnotetext{
${ }^{1}$ I would like to thank two anonymous reviewers for their valuable comments and critical feedback.
} 
strongly and weakly cartographic, a division in some ways reminiscent of the strong and weak version of Thráinsson's (1996) Structural Uniformity Hypothesis (SUH), below.

The Structural Uniformity Hypothesis (Thráinsson 1996: 255)

(a) Strong Version

Clausal architecture is completely determined by UG in the sense that all clauses in all languages have the same set of functional categories and their sequence (c-command relations) is uniform.

(b) Weak Version

Clausal architecture is determined by UG in the sense that UG defines a set of functional categories, $\left\{\mathrm{F}_{1}, \mathrm{~F}_{2}, \ldots \mathrm{F}_{\mathrm{N}}\right\}$, that languages "select" from. For any functional categories $F_{i}$ and $F_{j}$, the sequence will be uniform whenever they occur, i.e. if $\mathrm{L}_{1}$ and $\mathrm{L}_{2}$ each instantiate both $\mathrm{F}_{\mathrm{i}}$ and $\mathrm{F}_{\mathrm{j}}$ and if $\mathrm{F}_{\mathrm{i}} \mathrm{c}$-commands $\mathrm{F}_{\mathrm{j}}$ in $\mathrm{L}_{1}$, then $\mathrm{F}_{\mathrm{i}} \mathrm{c}$-commands $\mathrm{F}_{\mathrm{j}}$ in $\mathrm{L}_{2}$.

While (1a) seems to comply with Zwart's definition of fixed approaches, (1b) falls short of the true character of flexible ones; as Zwart (2007: 1) himself points out, "[a] weak cartographic approach might accept that not all projections need to be realized in full; just that when they are realized, they are bound to appear in a certain hierarchical order". Thus, Zwart's weakly cartographic flexible approach approximates some aspects of the Limited Diversity Hypothesis (LDH), yet another notion offered by Thráinsson.

\section{The Limited Diversity Hypothesis (LDH, Thráinsson 1996: 257)}

Clausal architecture is determined by UG in the sense that UG defines the set of functional categories $[\mathrm{FC}],\left\{\mathrm{F}_{1}, \mathrm{~F}_{2}, \ldots \mathrm{F}_{\mathrm{N}}\right\}$, that languages "select" from. Cross-linguistic and intra-linguistic variations are limited to the following:

(a) It is not the case that all FCs are instantiated by all languages.

(b) The FCs selected by a given language may not be present in all clause types of that language

(c) The sequence (c-command relations) of those functional categories (dominance relations between functional projections) that are directly related to morphological distinctions may vary from language to language, consistent with Mirror Principle (Baker 1985).

The formulation of sentence architecture along the lines suggested by LDH clearly parts with the universal format originally present in the analyses of Cinque and Rizzi. A weakly cartographic approach defined in terms of LDH has to cope with the explanatory "give-and-take", i.e. the price it has to pay for abandoning the universal format, 
plausibly a part of UG. On the other hand though, an approach postulating the absence of any "pre-engineered" syntactic hierarchies would have to be shaped solely by the computational properties of Merge and Move, a promising perspective. For the purpose of the analysis then, I will assume that a FLEXIBLE ${ }^{2}$ model of syntax respects (2a) and $(2 b)$, yet it makes no recourse to a potential configuration of c-command relations between the functional categories $\left\{\mathrm{F}_{1} \ldots \mathrm{F}_{\mathrm{N}}\right\}$. The task of UG is thus restricted to the provision of an unordered set of FCs, a generally desired result. ${ }^{3}$ Zwart adds yet another empirical argument in favour of the FLEXIBLE syntax; "[on] a weak dynamic approach, we might say that the map of the clause is an abstraction of the structure of different types of clauses [...] there is a reason to believe that such an abstraction is impossible, because of the existence of order transitivity failures (Zwart 2007: 2). In structure-building terms, it appears to share a number of relevant features with some derivational late-minimalist systems (e.g. Collins 2002; Frampton and Gutman 2002), as shown in the section below.

\subsection{The story of Locus, Pivot and Derivational (work)Space}

A brief look at the characteristics of the proposals put forward by, among others, Collins (2002), Frampton and Gutmann (2002), Epstein and Seely (2002) and Zwart (2007) reveals clear parallels between their structure-building mechanisms. Most importantly, they share some common intuitions concerning the motivation for syntactic operations Merge \& Move, which is aptly captured by Collins (2002) in his notion of Locus:

Let $\mathrm{X}$ be a lexical item that has one or more probe/selectors. Suppose $\mathrm{X}$ is chosen from the lexical array and introduced into the derivation. Then the probe/selectors of X must be satisfied before any new unsaturated items are chosen from the lexical array. Let us call $\mathrm{X}$ the locus $\mathrm{X}$ the derivation.

(Collins 2002: 46)

If a feature of a given probe fails to be satisfied/saturated at a particular point of the derivation (Locus), the subsequent insertion of another LI with uninterpretable/un-

\footnotetext{
${ }^{2}$ For the sake of distinguishing between the non-cartographic approaches as proposed by Zwart (among others) and the "weakly cartographic" approaches, throughout this article I will be using capital letters to refer to the former (i.e. FLEXIBLE).

${ }^{3}$ An assumption that dovetails with Chomsky's formulation of a truly explanatory theory of $\mathrm{FL}_{\mathrm{H}}$. The defining criteria for such a theory are: (1) show how language $\mathrm{L}$ is derived from a uniform initial state $\mathrm{S}_{0}$ under the "boundary conditions" set by experience, (2) present the rules of grammar in the simplest form (3) factor out overarching principles, reduce the system to "virtual conceptual necessity" (Chomsky 2000, 2001).

${ }^{4}$ The discussion focuses on a number of syntactic phenomena ranging from Focus/Topic placement (Van Craenenbroeck 2006), adverb ordering (Nilsen 2003), argument adjunct interaction (Bobaljik 1999), etc., see Section 3.2.1.
} 
valued features causes the derivational space to be occupied by two unsaturated LIs at the same time, thereby crashing the derivation, as in (3).

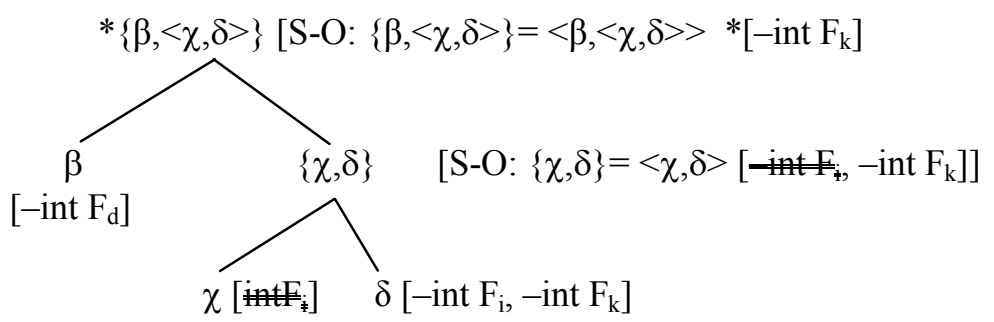

The illegitimate series of Mergers in (4) illustrates the point; the derivation crashes at $\mathrm{v}^{\prime}$ due to the introduction of $\mathrm{T}^{0}$ with its own set of uninterpretable features without prior checking of v's external $\theta$-role. ${ }^{5}$

...will see Mary

(a) MERGE (see, Mary) $=\{$ see, Mary $\}-\theta$-role/feature valued

(b) MERGE (will, $\{$ see, Mary $\})=\{$ will, see Mary $\}$

According to Collins, the Locus-based system allows to minimize the necessary lookback to the previous operation, a natural assumption to be made given the impossibility of having two lexical items, each with a set of uninterpretable features within the same derivational space, as in (3).

Frampton and Gutmann (2002), in their crash-proof system, incorporate a similar model, i.e. the Pivot;

\begin{abstract}
In this system, a derivation is a series of cycles. Each cycle is triggered by the introduction of a new head. Certain features of that head, called the pivot, must be satisfied before a new cycle is undertaken. First every selectional feature of the pivot [at a given point in the derivation] must be satisfied by merger with phrases headed by previous pivots. After the selectional needs of the pivot are satisfied, certain "attracting features" of the pivot must be satisfied by agreement.
\end{abstract}

(Frampton and Gutmann 2002: 97)

It is worth noticing that the derivational systems presented above do not utilize Numeration/Lexical Arrays; these become spurious (non-optimal), as claimed by Collins in his earlier works:

\footnotetext{
${ }^{5} \theta$-roles acquire a feature-like status (e.g. Hornstein 1999).
} 


\begin{abstract}
The presence of Numeration in the theory of grammar is not necessary in the same way the lexicon and the PF and LF interfaces are necessary. The Numeration is purely grammar internal that is observed only through its consequences for observable structures generated by the grammar.
\end{abstract}

(Collins 1997: 90) ${ }^{6}$

Another argument raised by Chomsky (2001) in favour of the reduced computational workspace concerns the timing of the valuation of uninterpretable features; after they are valued, the distinction is lost and interpretation without reconstruction is impossible. It is thus proposed that Spell-Out should occur shortly after the valuation in order to reduce look-back. Epstein and Seely (2002) incorporate essentially the same observation in their system, i.e. each transformational rule constitutes a phase (their null hypothesis).

Zwart's (2007) concept of a FELXIBLE computation sheds some more light on the issues related to the formulation of the derivational Locus/Pivot. In fact, Zwart assumes a supposedly inherently asymmetric relation whereby "an element $\alpha$ is merged to a workspace $\delta$ ". The necessary conditions are represented in (5) and (6):

(5) For P, a derivation (i.e. a syntactic object derived by Merge) and $\delta$, the derivational workspace of $\mathrm{P}$

(a) $\mathrm{P}=\delta$ before the merger of $\alpha$ to $\delta$

(b) $\mathrm{P}=\langle\alpha, \delta>$ after the merger of $\alpha$ to $\delta$

(6) (Zwart's (1)) [G]iven a workspace $\delta$ of a derivation P, and an element $\alpha$ merged to $\delta$, the position of $\alpha=\operatorname{OCC}(\delta)$ in $\mathrm{P}$.

Zwart (2007: 3) adds that "only elements merged to the workspace have a syntactic position [...] the operation Merge creates them, but not positions them"; see (7).

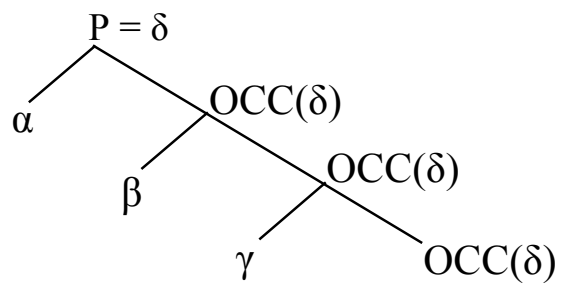

\footnotetext{
${ }^{6}$ The problem is exemplified by the (conceptually dubious) phase-based resolution of the Merge-over-Move issue in the account of existential EXPL constructions, see (i) and (ii).

(i) There ${ }_{i}$ seems $\left[t_{i}\right.$ to $\left[{ }_{v p}\right.$ be a man in the room $\left.]\right]$.

(ii) *There seems [TP a $\operatorname{man}_{\mathrm{i}}$ to $\left[{ }_{\mathrm{vp}} \mathrm{t}_{\mathrm{i}}\right.$ be in the room]].
} 
The formulation of (6), although in some ways convergent with the idea of Locus/ Pivot, has an appealingly (at least, on the conceptual level) minimalist flavor; it takes Merge to be the structure-building operation driving syntactic computations.

In essence then, the computational models discussed in this section display the following set of features.

(8i)

(a) syntactic derivations are driven by the necessity to check/value features borne by LIs;

(b) syntactic derivations consist of highly constrained, sequenced series of Mergers

(c) each Merger results in the formation of a new syntactic object/feature checking - valuation;

(d) at a given point of the derivation (Locus/Pivot/ $\delta$ ) certain syntactic relations (fed by checking/valuation) are established, i.e. no need arises to reconstruct to the earlier stages of the derivation;

(e) each merger constitutes a separate unit, a phase;

(f) Extension Condition ${ }^{8}$ is respected;

(g) look-back is restricted to the previous operation;

(h) no look-ahead (acquires a new look in non-cartographic approaches, see Section 2.1).

Table 1. Strongly derivational approaches - a comparative view.

\begin{tabular}{ccccc}
\hline $\begin{array}{c}\text { Properties } \\
\text { of derivation }\end{array}$ & $\begin{array}{c}\text { Epstein and Seely } \\
(2002)\end{array}$ & Collins (2002) & $\begin{array}{c}\text { Frampton and } \\
\text { Gutmann (2002) }\end{array}$ & Zwart (2007) \\
\hline A & $\sqrt{ }$ & $\sqrt{ }$ & $\sqrt{ }$ & $?$ \\
B & $\sqrt{ }$ & $\sqrt{ }$ & $\sqrt{ }$ & $?$ \\
C & $\sqrt{ }$ & $\sqrt{ }$ & $\sqrt{ }$ & $\sqrt{ }$ \\
D & $\sqrt{ }$ & $\sqrt{ }$ & $\sqrt{ }$ & $\sqrt{ }$ \\
E & $\sqrt{ }$ & $\sqrt{ }$ & $\sqrt{ }$ & $?$ \\
F & $\sqrt{ }$ & $\sqrt{ }$ & $\sqrt{ }$ & - \\
G & $\sqrt{ }$ & $\sqrt{ }$ & $\sqrt{ }$ & $\sqrt{ }$ \\
H & $\sqrt{ }$ & & & \\
\hline
\end{tabular}

${ }^{7}$ It is unclear, however, if $\mathrm{OCC}(\delta)$ is supposed to be $\delta$ only, say XP, a label, or whether it is the XP and all the categories it contains. In any case, defining the position of a newly merged LI on the basis of derivational sisterhood seems suspicious for reasons yet to be explained.

${ }^{8}$ More recently, as Chomsky (2005: 5) reformulates Extension Condition as No Tampering Condition; "Merge of X and Y leaves the two S[yntactic]O[bject]s unchanged [...]. Merge cannot break up X or Y, or add new features to them".

${ }^{9}$ The moot points, marked as ? or $? / \sqrt{ }$, will be referred to in the latter sections of this paper. 
As (8ii) shows, there is a considerable overlap in the derivational procedures they apply, particularly in terms of transparency/opacity of the derivation. Let us now subject (8ah) to some empirical tests.

2. The nuts and bolts of the strongly derivational (dynamic) approaches

This section examines the compatibility of the approaches mentioned in Section 1.1, the LCA (Kayne 1994) and BPS (Chomsky 1994). The major assumption is that they fail to observe some basic structure-building mechanisms necessary for linearization/specification of syntactic positions. Additionally, I discuss here some potentially problematic data (concentrating mostly on the so-called left periphery) in order to show that the strongly derivational/FLEXIBLE approaches of the type discussed above do not offer any convenient ways of handling certain long-distance morpho-syntactic relations.

2.1. The legacy of LCA (Kayne 1994) and Bare Phrase Structure (Chomsky 1994); Asymmetry and $\mathrm{X}^{\prime}$-invisibility taken seriously

On conceptual grounds, Epstein and Seely's null hypothesis (8e) yields some appealing consequences for the competence-performance interface (see also Frampton and Gutmann 2002). Yet, in empirical terms, an approach respecting (8e) will inevitably have to face a number of problems concerning the structural description of the operation Merge as well as linearization of the derivation. These emerge once Kayne's (1994) and Chomsky's (1994) observations on linearity and the status of non-branching/intermediate projections, formulated respectively as Linear Correspondence Axiom (LCA) and Bare Phrase Structure (BPS), are taken into consideration. Let us first deal with the linearity problem as defined in LCA.

LCA is based on three major conditions, i.e. transitivity, totality and asymmetry. Thus, (10a) and (10b) overleaf, both containing the non-terminal nodes X, Y and Z, with their respective terminal nodes $\{j\},\{m\}$ and $\{0\}$, differ minimally in that the former contains an additional non-terminal node $\mathrm{F} .^{10}$

(9) forces the following set of asymmetric c-command dependencies:
(a) $\mathrm{T}=\{\mathrm{j}, \mathrm{m}, \mathrm{o}\}$
(b) $\mathrm{A}=<\mathrm{X}, \mathrm{Y}>,<\mathrm{X}, \mathrm{Z}>,<\mathrm{X}, \mathrm{F}>,<\mathrm{Y}, \mathrm{F}>$
(c) $\mathrm{d}(\mathrm{A})=\{\mathrm{j}, \mathrm{m}\},\{\mathrm{j}, \mathrm{o}\},\{\mathrm{m}, \mathrm{o}\}$

\footnotetext{
${ }^{10}$ To derive the required relations, Kayne introduces some useful technical terms/dependencies between lexical items; thus $A$ is the set of ordered pairs of non-terminals such that the first item asymmetrically ccommands the other, $\mathrm{T}$ is the set of terminals of a given phrase marker $\mathrm{P}$ and $d(\mathrm{X})$ is the set of terminals that X dominates. Given A, T and d, the LCA assumes that d(A) is the linear ordering of T (Kayne 1994: 6).
} 
(10a)

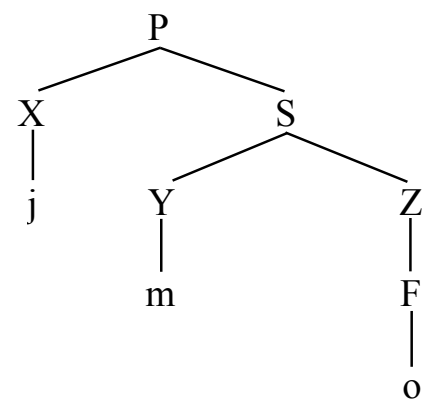

(10b)

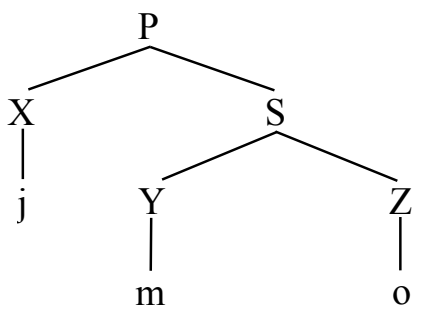

As (9c) shows, the relation between the terminals is indeed transitive, total and asymmetric. Crucially though, this result can only be obtained if $F$ is present in the structure. ${ }^{11}$ Otherwise, the required set of dependencies fails to be total and transitive and linearization is impossible, as shown in (11):

(11) (10b)

(a) $\mathrm{T}=\{\mathrm{j}, \mathrm{m}, \mathrm{o}\}$

(b) $\mathrm{A}=\langle\mathrm{X}, \mathrm{Y}\rangle,<\mathrm{X}, \mathrm{Z}\rangle$

(c) $\mathrm{d}(\mathrm{a})=<\mathrm{j}, \mathrm{m}>,<\mathrm{j}, \mathrm{o}>, *<\mathrm{m}, \mathrm{o}>$

Chomsky's (BPS) offers an alternative analysis on which "phrase structure representation is 'bare', excluding anything beyond lexical features and objects constructed from them" (Chomsky 1994: 245). Its properties can be captured in terms of Myusken's (1982) feature system:
(a) $[+]$ projected, $[+]$ maximal $-(\mathrm{XP})$
(b) $[+]$ projected $[-]$ maximal $-\left(\mathrm{X}^{\prime}\right)$
(c) $[-]$ projected $[-]$ maximal $-\left(\mathrm{X}^{0}\right)$
(d) $*[-]$ projected $[+]$ maximal - (untenable)

Crucially though, Chomsky (1994: 242-243) wants to dispense with the X'-level claiming that " $[\mathrm{a}]$ category that does not project any further is a maximal projection XP, and one that is not a projection at all is a minimal projection $\mathrm{X}^{\mathrm{min}}$; any other is an $X^{\prime}$, invisible at the interface and for computation".

It should be noted that both the systems, although differing in a significant number of ways, share common assumptions concerning the obligatorily asymmetric character

\footnotetext{
${ }^{11}$ According to Kayne (1994: 16-17), "unless there turns out to be another natural way to permit specifiers within the theory developed here, the conclusion must be that a specifier is necessarily to be taken as an adjoined phrase, involving crucial use of the segment/category distinction".
} 
of syntactic mergers. Thus, any potentially symmetric operations, e.g. between $X^{\mathrm{min}}$ and its complement (as shown in 13) will, according to Kayne, involve the raising of the latter and creation of an asymmetric configuration;

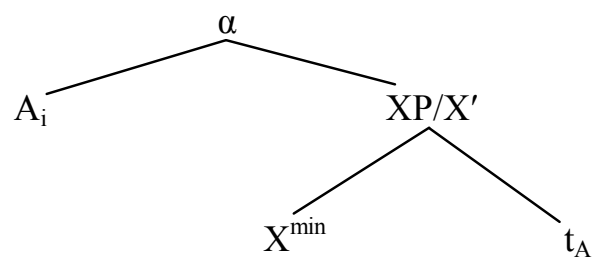

Thus, if $\mathrm{A}$ is a bare head, say $\mathrm{N}^{0}$ and $\mathrm{X}$ is a gerund ${ }^{12}, \mathrm{~N}^{0}$ will obligatorily move up, as witnessed in (14a).

(14) (a) I love book/*books reading.

(b) I love reading *book/books.

In (14b), however, books, an intricately structured DP, stays in-situ without giving rise to the violation of LCA.

As for the status of intermediate projections in BPS, Chomsky assumes that "from a representational point of view, there is something odd about a category that is present but invisible; but from a derivational perspective [...] the result is quite natural, the objects being 'fossils' that were maximal (hence visible at an earlier stage of the derivation, targeted by the operation that renders them invisible".

The conditions defined above as asymmetry and $X^{\prime}$-invisibility pose a good deal of problems for the strongly derivational approaches to syntax postulating the minimized, truncated derivational workspace along the lines of (8), in particular (8e). These have to do with (a) the lack of asymmetry in the proposed syntactic relations, (b) the identification and positioning of newly merged/remerged lexical items. Unless these are addressed with satisfactory results, the computational models sketched in Section 1.1 face an imminent risk of running into too much unwelcome stipulation. Consider the point Zwart (2007) makes with reference to the relation between a yet-to-be-merged LI and the derivational workspace:

We take Merge in its simplest form to be an assignment operation which takes an element from a certain resource (Numeration of Chomsky 1995) and assigns it to a workspace (the current derivation under construction). As pointed out by Jaspers (1998), such an operation is inherently asymmetric, in the sense

\footnotetext{
${ }^{12}$ As Barrie (2005) claims, English gerunds can select for either $\mathrm{N}^{0}$ or an NP/DP.
} 
that its product contains a previously existing part (the current stage of the
derivation) and a newly added element (the element merged).

(Zwart 2007: 1)

What are the factors that make Merge an inherently asymmetric relation? Consider the characteristics of merging a LI $\alpha$, a head, with a set of features F into the derivation(al space) at a given point $\beta$;

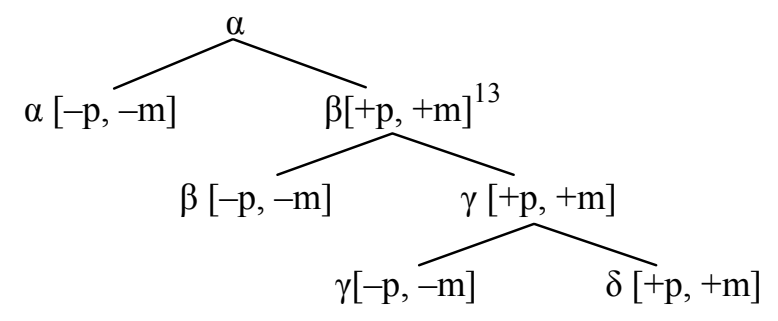

According to LCA, the relation between the head $\alpha$ and its complement $\beta$ will be linearized if the head $\alpha$ establishes asymmetric c-command with the terminals of $\beta$, either on merging $\alpha$ with $\beta$ (LCA-driven syntactic computation) or at the point of transfer to $\mathrm{PF} / \mathrm{LF}$ (LCA-driven phonological linearization). In any case, $\beta$ allows some (apparently limited) insight into its contents, needed for linearization purposes ( which can be delayed until PF-split) as well as the positioning of $\alpha$, a newly merged element. What is $\beta$ $[+\mathrm{p},+\mathrm{m}]$ then? Let us have a look at (16), in which $\beta$ is taken as the output of a syntactic operation, equivalent to a label, as evidently dictated by (8e).

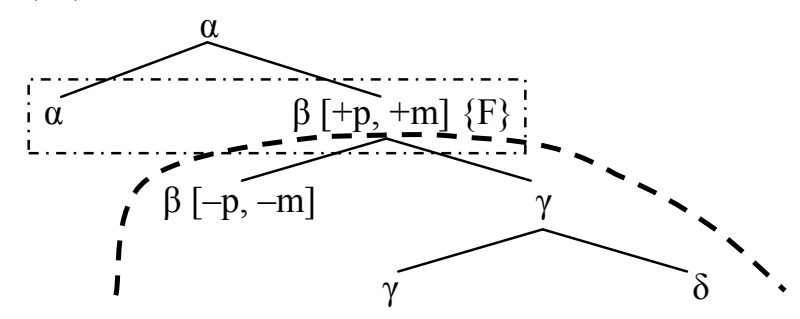

Despite the fact that $\beta$ possesses a set of features $\{F\}$, the record of its derivational history, the structural relation between $\alpha$ and $\beta$ is in no way asymmetric (see $9 a$ ). Within the derivational space there are only two objects available, namely $\alpha$ and $\beta$ ( $\beta$-a phase with its content spelt-out). To enable linearization, the non-projecting element $\beta$ has to

${ }^{13}[+/-$ projected]/[+/-maximal], as proposed by Myusken (1982), see (12). 
raise up (see 13). On assumption that each step of the derivation is followed by SpellOut (8e), the procedure is necessarily reiterated at every step of the derivation until all the Numeration is exhausted. As witnessed in (17), the derivation is thus massively complex:

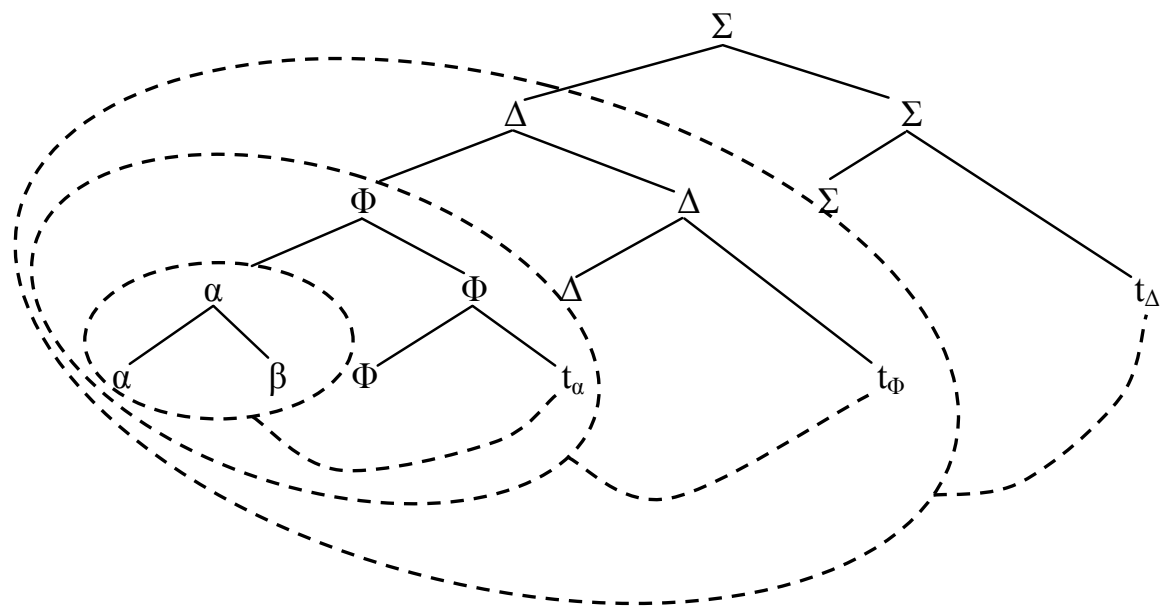

Thus, the merger of $\Phi$, a head, into the derivational workspace consisting of $\alpha$, a nonhead, forces the movement of the latter to a higher position in order to establish a (vacuous) asymmetric c-command relation. In the illustrated configuration, $\alpha$ will now vacuously asymmetrically c-command $\Phi$ as, in fact, in order to be c-commanded by $\Phi$, $\alpha$ would have to be dominated by all the segments of $\Phi .{ }^{14}$ Next, the derivational workspace marked as $\Phi$, a label, merges with $\Delta$, a head, resulting in $\Phi$ moving up. An analogous situation is encountered once $\Sigma$ is introduced into the derivation. Construed in this way, the computation in (17) seems far from economical. There are two ways in which the unwanted overgeneration can be restrained. Primarily, as Barrie (2005) suggests, it is the introduction of a null head; supposing $\Phi$ has no phonological content, its linearization with respect to $\alpha$ will not cause the latter to move. For that reason, $\Delta$ is allowed to establish asymmetric c-command relations with both $\alpha$ and $\Phi$. Once $\Sigma$ is merged, the asymmetric c-command relation is established between $\Sigma$ and $\Delta, \Phi$ placed in-situ. Yet, according to Barrie, for this scenario to work, "we must allow heads to occupy complement and specifier positions as BPS dictates and we must ignore phonologically empty heads for the purpose of linearization".

Let us now focus on the supposedly inherently asymmetric nature of Merge. Consider the properties of Merge, adopted here after Chomsky (1999), listed as (18):

\footnotetext{
${ }^{14}$ The idea strongly reminiscent of Chomsky's (1986) adjunction used to account for successive-cyclic movement.
} 
The indispensable operation of a recursive system is Merge (or some variant of it), which takes two syntactic objects $\alpha$ and $\beta$ and forms a new object $\Gamma=$ $\{\alpha, \beta\}$. We assume further that $\Gamma$ is of indeterminate type: it has label LB $=$ (Г). [...] Iterated Merge, required in any recursive system, yields Contain (equivalently, a term-of). Arguably Merge also yields a relation between $\alpha$ and $\beta$ (sister); transitive closure yields c-command (and also Contain and Identity, presumably available independently) (Chomsky 1999: 2).

(18) Merge

(a) is a binary operation;

(b) allows one of the LIs to project (Bare Phrase Structure) and label the newly created object;

(c) when recursive, yields Contain (look-into);

(d) allows to identify the newly merged LI by referring it to the existing item.

Crucially, (18c) and (18d) are available only if the item is a syntactic object, not a sole label, thus they are unattainable for $\beta$ defined as in (16). To conclude, the inherently asymmetric (and thus LCA-compliant) nature of Merge is derivable naturally on condition that a newly merged LI has access (at the point of merger) to the content of the other constituent in order to establish asymmetric linearity relations. Otherwise, the asymmetry of Merge becomes a stipulated condition, a non-trivial problem for syntactic approaches that allow (8e). A plausible evasion of the above condition offered by Collins (2002, earlier Collins and Ura 2001) is to allow insight into the previous operation in the derivation, their Accessibility Condition, presented here as (19):

(19) Accessibility Condition (AC)

A lexical item X (and the features it contains) is accessible without search to a syntactic operation OP if X contained the probe / selector for the last operation in the derivation.

AC operates in (20), where the verb selects for and agrees with on, the substrate of the previous Merge.

(20a) tell on John

(20b) tell [on [John]]

In terms of LCA, (21a) and (21b) are analogous to (10a) and (10b).

In (21a), the PP $(\beta)$ is regarded as a label, i.e. a syntactic word that has already been spelt-out. Unless any additional steps are taken, the sole application of Merge will not establish any asymmetric c-command relations and the structure will not be linearized. In (21b), however, the PP is "transparent" to the verb, thereby allowing LCA to operate. 
(21)
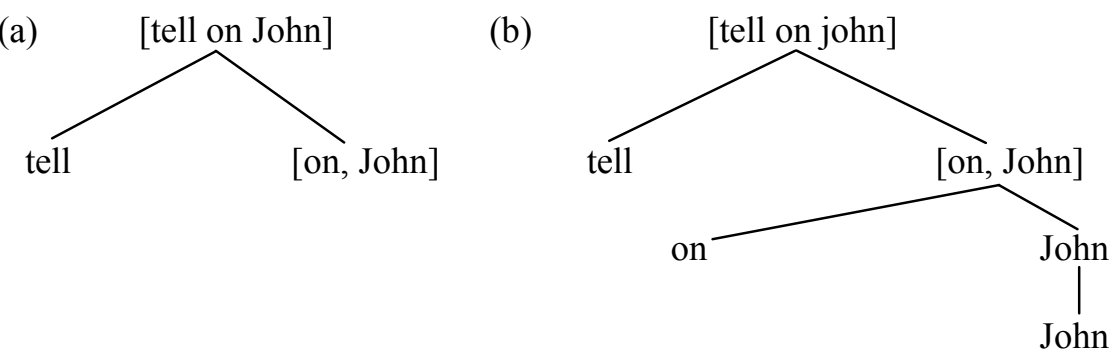

To conclude, it is not clear then how strictly derivational computations naturally derive the asymmetric nature of Merge. Rather, it seems that Merge itself is a simple syntactic operation forming binary structures (thus concatenating two lexical items at each point), its asymmetry resulting from the fact that the structure of one of these items is (at least to some extent) transparent (see $18 \mathrm{c}-\mathrm{d}$ ).

The apparent lack of asymmetry brings us directly to the other problem, i.e. the identification and positioning of newly merged/remerged lexical items. At this point various configurations should be analyzed. For example, let $\alpha$ be a non-head (XP) moved and subsequently remerged (Internal Merge, using Chomsky's 2001 terms) into the derivational workspace. Consider once again the way in which the position of a newly merged LI, is specified (22).

(Zwart's (1)) [G]iven a workspace $\delta$ of a derivation P, and an element $\alpha$ merged to $\delta$, the position of $\alpha=\operatorname{OCC}(\delta)$ in $\mathrm{P}$.

(22) takes derivational sisterhood to be the fundamental relation specifying the merged elements at a given point of the derivation (see also Frampton and Gutmann 2002; Collins 2002). Yet, how to define the landing/re-merger site of $\alpha$, an XP moved up and remerged back into the structure as illustrated in (23)?

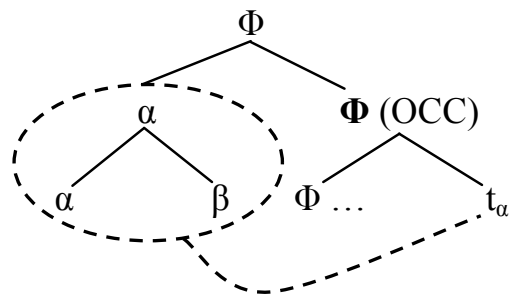

In other words, what is the status of the boldfaced $\Phi$, i.e. the derivational workspace? In BPS terminology (see 12), $\Phi$ counts as XP, to be converted (at a later stage) into X', 
thus invisible for the syntactic component (see Chomsky 1994). However, in a strongly derivational system such "restructuring" is far from well-motivated; $\Phi$ (a phase) constitutes a spell-out domain, a syntactic word that is inaccessible from outside/resistant to internal tampering (see No Tampering Condition, Chomsky 2005). Alternatively, it may be assumed that $\alpha$ gets adjoined to $\Phi$, a solution akin to the LCA-based treatment of specifiers. Yet, as matters stand, the formulation of $\Phi$ in (24) seems at best obscure.

(24) The position of $\alpha=\boldsymbol{\Phi}$ (OCC)

Alternatively, as Zwart suggests, the asymmetric nature of Merge can be derived from the temporal asymmetry between a newly merged item and the existing syntactic object. Zwart (2007) and Zwart and Fortuny (2008) aim to resolve the problem by revoking Jasper's (1998) notion of temporal asymmetry. Consider the application of LCA in (25), presented in detail in (26).

$(25)<\mathrm{a},<\mathrm{y}, \mathrm{z}>>\rightarrow<\mathrm{a}, \mathrm{y}, \mathrm{z}>\rightarrow[\mathrm{LCA}] \rightarrow<\mathrm{a} \mathrm{y} \mathrm{z}>$

(26) Derivation (D) ${ }^{15}$

$\mathrm{N}($ umeration $)=\{\mathrm{a}, \mathrm{y}, \mathrm{z}\}$

(a) Select a, yielding $\mathrm{N}=\{\mathrm{y}, \mathrm{z}\}$ and $\mathrm{D}=<\mathrm{a}, \mathrm{N}>$

(b) Select y, yielding $\mathrm{N}=\{\mathrm{z}\}$ and $\mathrm{D}=<\mathrm{a},<\mathrm{y}, \mathrm{N}>$

(c) Select $\mathrm{z}$, yielding $\mathrm{N}=\varnothing$ and $\mathrm{D}=<\mathrm{a},<\mathrm{y}, \mathrm{z}, \mathrm{N}>>$

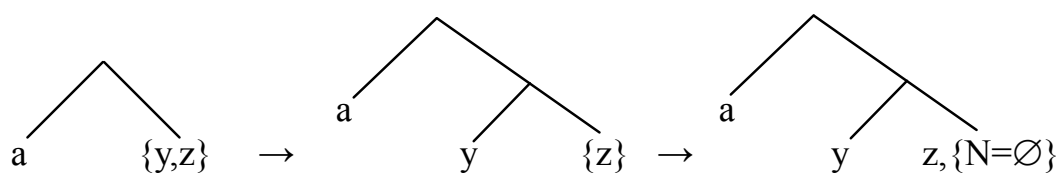

The derivation in (26) supposedly overcomes the problems of the representational (global) LCA, specifically the need to postulate non-branching projections for the sake of retaining asymmetry (see 9a). Order is the function of Merge, i.e. linearization depends on the chronological insertion of LIs and, established at each step of the computation. In some respects then, it derives the effects of both LCA and BPS, a desired result.

The approach requires a necessary stipulation though. To preserve asymmetry, the elements placed at the left branch $(a$ in 25,26$)$ must have a simplified structure, i.e. they should be represented as a sole syntactic label.

\footnotetext{
${ }^{15}$ It should be noticed that (16) is a top-down derivation. Yet, Zwart and Fortuny (2008) present an alternative for both top-down and bottom-to-top computations. The directionality does not seem to affect the reasoning presented in (25-27).
} 
Let us consider a derivation in which the element merged at the left branch is itself structured, as in (27):

\section{Derivation (D)}

Numeration $=\{$ the, boy, left $\}$

(1) Select the, yielding $\mathrm{N}=\{$ boy, left $\}$ and $\mathrm{D}=<$ the, $\mathrm{N}>$

(2) Select boy, yielding $\mathrm{N}=\{$ left $\}$ and $\mathrm{D}=<<$ the, boy $>, \mathrm{N}>/ /<$ the, $<$ boy, $\mathrm{N}>>$ ??

(3) Select left, yielding $\mathrm{N}=\{\varnothing\}$ and $\mathrm{D}=<<$ the boy $>$ left $>/ /<$ the, $<$ boy, left $>>$ ??

(27a)

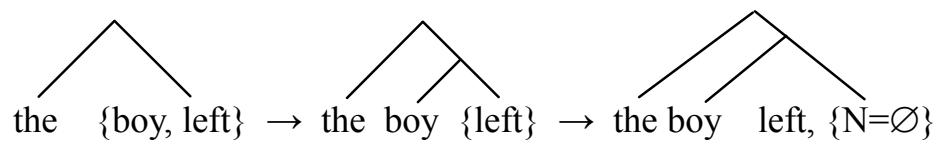

(27b)

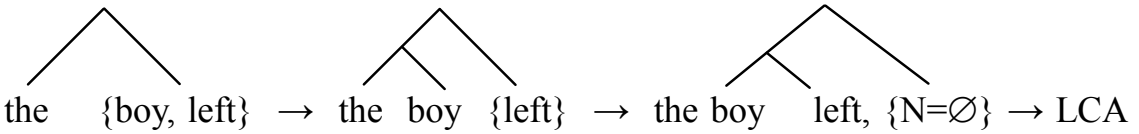

$\rightarrow$ left the boy ???

(27) offers two conflicting alternatives; in (27a), the LCA, operating upon the sequence of mergers, establishes the accurate order ( $<$ the, boy, left $>\rightarrow<$ the boy left $>$ ). Still, it fails to derive the proper constituent structure. In (27b), in turn, the and boy merge first, forming a constituent. However, the merger of left poses problems for Jasper's (1998) temporal asymmetry, as, this time, this is the verb that is merged "into an already existing structure"; in that case, the temporal asymmetry would instruct LCA to incorrectly derive $<$ left, the boy $>\rightarrow<$ left the boy $>$. ${ }^{16}$ In order to retain Jasper's proposal, the derivation would have to allow two simultaneous computations, "the left edge" vs. "the rest" and, subsequently, collapse the former, thus converting it into a label. ${ }^{97}$ However, such a procedure seems conceptually void. First, by definition, there is only one deriva-

\footnotetext{
${ }^{16}$ The $P S i C L$ reviewer suggests that "[it] is not really a problem, as Zwart allows the output of previous derivations [...] to be a part of the Numeration". It is unclear to me how the DP the boy should become a part of the Numeration unless there are two cyclic derivations proceeding simultaneously. Yet, such an idea clearly parts with the assumption that order is the function of Merge, as that requires a one-at-a-time selection of LI into the syntactic computation.

${ }^{17}$ If this system derives the linear ordering on the basis of the sequences of Merge only, the asymmetry might potentially be restored by introducing empty functional heads (e.g. little v in 27). However, if the explanatory potential of the theory is to be retained, their presence should be independently motivated; otherwise, the approach will face an enormous proliferation of (stipulated) functional projections.
} 
tional space. Secondly, given two simultaneous derivations, the syntactic component would require principled instructions as to which one should be linearized first (i.e. treated as "the left edge"). ${ }^{18}$

It appears then that the position of $\alpha$ in (24) cannot be defined on strict application of derivational sisterhood only (compliant with 8e). The observation gives leeway to the not-so-reductionist approaches that allow limited look-back and look-ahead options, e.g. systems allowing locally representational steps (against 8e, g, h) (Cegłowski 2006).

To the extent the fundamental phrase structure building mechanisms require linearization, asymmetry must be obtainable. As such, it does not seem to emerge as an inherent feature of Merge. Rather, a truly minimalist assumption is that the operation is $b i$ nary, asymmetry naturally resulting from the (restricted) transparency of the so-called derivational workspace understood as a syntactic object rather that a label. Whereas labels have some featural make-up, their content stays impenetrable, as expected on Epstein and Seely's (2002) null hypothesis (8e). This, in turn, renders linearization unattainable, a serious problem for the strongly derivational systems described in Section 1.1.

3. Arguments for Thráinsson's (1996) Limited Diversity Hypothesis and against Zwart's (2007) Escape

In his article, Zwart (2007) proposes to capture wh-/Topic- movements as the so-called inner conflicts within the derivational space, prompting extraction and subsequent raising of the offending element. The essence of the procedure is given underneath:

\begin{abstract}
The non-cartographic approach does not describe fronting as movement to a particular landing site (say, spec, CP), but as externalization of particular elements out of a certain stage of the derivation (essentially TP). On this approach, there is no "strong feature" residing in C which forces Spec, CP to be filled
\end{abstract}

(Zwart 2007: 12, emphasis added)

The mechanics of the inner-conflict-fueled system look appealingly simple; consider Topicalisation and wh-fronting, as shown in (28) and (29) (Zwart's 24-27):

(a) topic
Dat boek ken
jij niet
that book know:2SG.INV you not
'[You] don't know this book.'

${ }^{18}$ This in principle might be encoded in the featural make-up the syntactic objects. 
(b) wh-phrase

Welk boek ken jij niet

which book know:2SG.INV you not

'Which book don't you know?'

(29a) $\quad\left[\mathrm{CP} 2\left[\mathrm{CP} 1\right.\right.$ dat boek $\mathrm{C}_{1}[$ TP jij niet (...) $\left.\left.]\right]\right]$

(29b) $\left[\mathrm{CP} 2\right.$ welk boek $\mathrm{C}_{2}\left[{ }_{\mathrm{CP} 1} \mathrm{C}_{1}[\mathrm{TP}\right.$ jij niet (..) $\left.\left.]\right]\right]$

In (28a and 29a), the movement of the topic is not driven by any strong features; dat boek raises (actually, it is expelled) in order to escape an inner conflict within the TP marked as comment. Analogously, in (28b and 29b), the wh-focus has to be freed from the shackles of TP-ground.

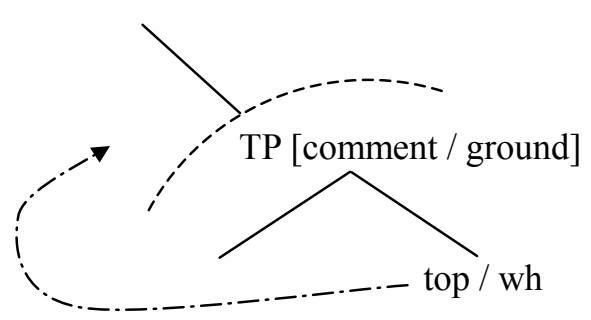

Sentence-initial adverbials, difficult to position on strictly cartographic grounds, ${ }^{19}$ are said to pattern analogously:

Zwart's (27)

(a) dat gisteren Jan het boek gelezen heeft that yesterday John the book read:PART have:3SG. 'that yesterday John has read the book'

(b) *gisteren Jan heeft het boek gelezen yesterday John have:3SG the book read:PART

(c) gisteren heeft Jan het boek gelezen yesterday have:3SG John the book read:PART

\footnotetext{
${ }^{19}$ The discussion is couched within a broader context, i.e. the syntactic status of subject-initial main clauses in Continental West Germanic languages (see Den Besten 1977).
} 
Thus, according to Zwart (2007: 12) "gisteren is a topic [...]; topics are removed from unmarked propositions ("TP") in Continental West Germanic, i.e. merged anew, followed by erasure of the topic from its position inside the proposition".

The following discussion focuses on two major areas considered problematic for this approach, namely: (a) the transfer of morphosyntactic information and (b) the nature of merge-erase system in the context of conflicting requirements on extraction. For convenience, it goes beyond the realm of Germanic syntax and consider some a number of interesting facts.

\subsection{The transfer of morphosyntactic information}

By definition, uninterpretable features on lexical items ensure that in the course of the syntactic computation, a given LI $\alpha$ will establish a relationship with another LI $\beta$ resulting in the valuation of features, visible through Move or its prerequisite, Agree. Yet, on Zwart's FLEXIBLE approach, this relation is largely reduced; the landing site (say, spec, CP, FocP, TopP, etc.) is simply unidentifiable. Instead, as shown in (30), the unmarked proposition TP expels offending elements. In that respect, movement is no longer driven by uninterpretable features (e.g. wh, Foc, Top, C) and a lengthy bulk of descriptive apparatus is eliminated. Yet, the proposal fails to capture the fact that the specific morphosyntactic shape of a given LI selected from the Numeration and merged into the derivation may actually determine the selection of functional projections to be merged into the structure above the TP level. In that case, the minimization proposed in the FLEXIBLE account is only apparent; due to the specific featural make-up of the LI in question, the derivation needs to look beyond its current stage to ensure convergence at some later stages. In some particular configurations, the look-ahead stretches over a large portion of the computation, thus questioning the legitimacy of the strictly local derivational systems discussed in Section 1.1 (including Zwart's Escape). To illustrate the problem, I recall two interesting phenomena here, the interaction between Topic and Focus in Polish as well as the intricate properties of subjunctive constructions in Spanish.

Consider first the scopal interactions between fronted quantified phrases in Polish in examples involving the so-called Object Fronting and True Topicalisation (Tajsner and Cegłowski 2006):

(32a) I co, nic nie napisaliście ?!

'And what, you wrote nothing.'

$$
\begin{aligned}
& \text { KażdyFoC coś napisał. } \\
& \text { Everybody something wrote } \\
& \text { 'Everybody wrote something.' } \\
& \text { every>some }
\end{aligned}
$$


$(32 \mathrm{c})$

$$
\begin{aligned}
& \text { Coś każdy } y_{\mathrm{FOC}} \text { napisal. } \\
& \text { Something everybody } \text { wrote } \\
& \text { 'Everybody wrote something.' } \\
& \text { every>some }
\end{aligned}
$$

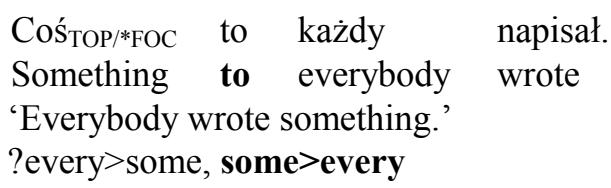

The most natural interpretation of (32b) and (32c) allows for distributive reading only. (32d), on the other hand, accepts both. How should these facts be captured within the FLEXIBLE account though (e.g. Zwart 2007)? In other words, if order is a function of merge, then the two alternative sequences of every/some in (32b-c) should yield different interpretive properties. The facts receive a straightforward account if the quantifier $k a \dot{z} d y$ raises in both cases to a position c-commanding coś, say, the Distributive Phrase (DistP), placed over QP (the target of coś). In (32b) the movement is overt, whereas in (32c) it is covert. However, the most felicitous reading of (32d) implies that coś must have moved higher than $k a z d y$, i.e. to a projection above DistP. On the analysis proposed by Tajsner and Cegłowski (2006), coś moves to TopP, marked with a lexical marker to spec, TopP, marked with an overt to. The facts presented here receive a straightforward account in fixed configurations ${ }^{20}$ as shown below:

(33) $[$ CP ...[TopP [DispP [FocP $[\mathrm{QP}[\mathrm{TP} . .]]]]$.

The relatively fixed hierarchy of Top and Foc projections in Polish is further supported by the fact that a FOC-marked phrase cannot reach as high as the position of the specifier of to (on our account, the seat of True Topicalisation, see 32d).

Let us now have a closer look at some aspects of the C-T relation, particularly unwelcome from a non-cartographic perspective. Recall that the FLEXIBLE account, as proposed by Zwart (2007), explicitly rejects the view of an articulated left periphery as proposed by Rizzi (1997) or Cinque (1999) suggesting that whatever happens beyond the TP level pertains to the resolution of inner conflicts. Bearing that in mind, let us analyze the intricacies of subjunctive (SUBJ) constructions in Spanish. Spanish SUBJ occurs frequently in subordinate clauses and is characterized by a morphological marking on the embedded verb; see Table 2.

Interestingly, SUBJ in Spanish displays a number of intriguing long-distance dependencies. Among these is the fact that in embedded SUBJ clauses the choice of the

\footnotetext{
${ }^{20}$ For an elaborate discussion, see Tajsner and Cegłowski (2006). For a discussion concerning the interaction of Focus/Topic driven movements and Floating Inflection in Polish, see Cegłowski (2007).
} 
Table 2. Indicative-Subjunctive verb alterations in Spanish.

\begin{tabular}{cll}
\hline PERSON/TENSE & INDICATIVE & SUBJUNCTIVE \\
\hline PRESENT & leo & \\
1SG & lees & lea \\
2SG & lee & leas \\
3SG & leemos & leamos \\
1PL & leéis & leáis \\
2PL & leen & lean \\
3PL & & \\
\hline FUTURE & leeré & \\
1SG & leerás & \\
2SG & leerá & \\
3SG & leeremos & \\
1PL & leeréis & \\
2PL & leerán & \\
3PL & & leyera \\
\hline IMPERFECT & leía & leyeras \\
1SG & leías & leyera \\
2SG & leía & leyéramos \\
3SG & leíamos & leyerais \\
1PL & leíais & leyeran \\
2PL & leyían & \\
3PL & &
\end{tabular}

verb (tense) form is far more restricted than in the indicative (IND) ones, as illustrated by the set of examples quoted after Torrego and Uriagiereka (1992): ${ }^{21}$

\section{(34) [Tense sequence]}

(34a) Platón dice [ ${ }_{\mathrm{CP}} \mathrm{C}$ que Aristóteles \{lee/leía/leerá\} a Sócrates]. (Spanish)

Plato say-PRES-3.SG that Aristotle read-IND-\{PRES/PAST/FUT\}-3.SG to Socrates

'Plato says that Aristotle $\{\mathrm{reads} / \mathrm{read} / \mathrm{will}$ read $\}$ Socrates.'

(34b) Platón dijo [CP C que Aristóteles \{lee/leía/leerá\} a Sócrates]. (Spanish)

Plato say-PAST-3.SG that Aristotle read-IND-\{PRES/PAST/FUT $\}-3 . S G$ to Socrates

'Plato said that Aristotle \{reads/read Socrates.'

\footnotetext{
${ }^{21}$ Actually, the list of differences is longer and includes the use of speaker oriented adverbs, NEG-raising,
} NPI licensing and que (COMP) deletion, the last one observed by Gallego and Uriagiereka (2007). 
(35a) Platón quiere [cP que Aristóteles \{lea/*leyera/*leyere $\}$ a Sócrates]. (Spanish) Plato want-PRES-3.SG that Aristotle read-SUBJ-\{PRES/*PAST/*FUT $\}-3 . S G$ to Socrates

'Plato wants Aristotle to $\{\mathrm{read} / \mathrm{read} / \mathrm{will} \mathrm{read}\}$ Socrates.'

(35b) Platón quería [ср que Aristóteles \{*lea/leyera/*leyere\} a Sócrates]. (Spanish) Plato want-PAST-3.SG that Aristotle read-SUBJ- $\{*$ PRES/PAST/*FUT $\}-3 . S G$ to Socrates

'Plato wanted Aristotle to $\{\mathrm{read} / \mathrm{read} / \mathrm{will} \mathrm{read}\}$ Socrates.'

SUBJ embedded clauses exclude topicalisation/focalization driven movements, as witnessed in (36) and (37):

(36) Topicalisation (Torrego and Uriagereka 1992)

(36a) Aristóteles creía [CP que, en cuanto a la Tragedia, debía ...

Aristotle think-PAST-3.SG that, in respect to the Tragedy, must-PAST-3.SG

... haber tres unidades]. (Spanish)

there-be-INF three units

'Aristotle thought that, as far as Tragedy was concerned, there must be three units.'

(36b) *Aristóteles quería [cP que, en cuanto a la Tragedia, ...

Aristotle want-PAST-3.SG that, in respect to the Tragedy,

... hubiera tres unidades]. (Spanish)

there-be-SUBJ-PAST-3.SG three units

'Aristotle wanted that, as far as Tragedy was concerned, there were three units.'

(37) Focalisation (Torrego and Uriagereka 1992)

(37a) Juan dijo [ср que [muchas cosas [ $_{\mathrm{i}}$ [тр pro había visto $\left.\left.\mathrm{t}_{\mathrm{i}}\right]\right]$ ! (Spanish) Juan say-PAST-3.SG that many things have-PAST-3.SG seen

'Juan said that a lot of things he had seen!'

(37b) *Juan quería [ст que [muchas cosas i $_{\mathrm{i}}$ [тр pro viera $\mathrm{t}_{\mathrm{i}}$ ]! (Spanish)

Juan wanted that many things see-SUBJ-3SG

'Juan wanted a lot of things for him to see!' 
In the same spirit, indirect questions are impossible in embedded SUBJ constructions, see (38).

(38) Indirect questions

(38a) *Juan \{desea/pregunta\} [CP cuántos libros tengas]. (Spanish)

Juan $\{$ wish/ ask $\}-3 . S G$ how-many books have-SUBJ-3.SG

'Juan wishes/asks how many books you have.'

(38b) No sé [cp qué te diga]. (non-Peninsular Spanish)

not know-1.SG what CL-to-you say-SUBJ-3.SG

'I do not know what to tell you.'

This rather peculiar behavior of SUBJ embedded clauses does not fit in easily within a non-cartographic, actually any strongly dynamic, derivational approach respecting (8) for two major reasons. First, how is the discrimination between the available morphological forms of the verb (see 34 and 35) accounted for the at point of the derivation presented in (39a) vs. (39b)?

(39a) [ [vр... \{lee/leía/leerá\} a Sócrates]

read-IND-\{PRES/PAST/FUT $\}-3 . S G$

(39b) $\quad[$ vр $\ldots\{$ lea/*leyera/*leyere $\}$ a Sócrates $]$

read-SUBJ- $\{$ PRES/*PAST/*FUT $\}-3 . S G$

It appears that a strictly local analysis offered within the strongly derivational accounts does not suffice to explain the motivation for the morphological choices postulated above. To the extent that SUBJ/IND distinction might be taken to involve the defective/opaque $\mathrm{C}$, the computation needs to look ahead of the current derivational step and access the relevant information. In contrast to the strongly derivational computation, the phase-based system stands up to the test, as indicated in (40).

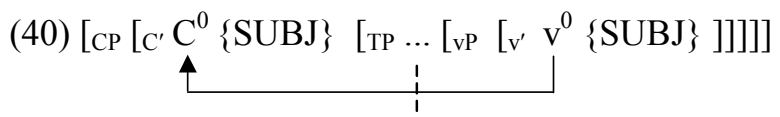

The above relation is predicted by Phase Impenetrability Condition, Chomsky (1999):

Phase Impenetrability Condition (Chomsky 1999: 10)

The domain of $\mathrm{H}$ is not accessible to operations outside HP, but only $\mathrm{H}$ and its edge, the edge being the residue outside H-bar, either Specs or elements adjoined to HP. 
It is not clear how the PIC effects could be incorporated in Zwart's escape system, which excludes any featural correlation between T and C; LI leave the TP only to resolve inner conflicts, definable at the TP level. Apparently though, the issue is even more complex; the SUBJ marking on embedded verbs commonly appears in conjunction with a specific set of matrix controllers, some of them listed in Table 3.

Table 3.

\begin{tabular}{ll}
\hline Spanish SUBJ controllers & English equivalents \\
\hline aconsejar & to advice, counsel \\
alegrarse & to enjoy, get merry \\
conseguir & to obtain, get \\
desear & to wish, desire \\
dudar & to doubt \\
$\quad$ ignorar & to ignore \\
$\quad$ lamentar & to lament \\
no saber* & not to know \\
no creer* & not to think \\
oponerse & to oppose \\
\hline
\end{tabular}

* Require SUBJ only when negated.

In view of this fact, the dependency in (40) has to be expanded;

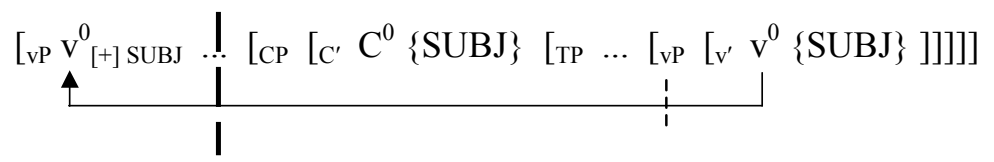

According to PIC, the embedded vP phase should be transferred to syntax once the derivation reaches the CP-level. If that were the case, it would be visible to the matrix $\mathrm{V}_{[+]}$suBJ/T as a frozen syntactic object, i.e. a syntactic word. Unless PIC is alleviated, the phase-based system has little if any principled account for tense sequence in (41). ${ }^{22}$ Whatever the exact formulation PIC-obviating effects in SUBJ constructions (e.g. phase sliding, see Pesetsky and Torrego 2001, 2004, 2007; Gallego 2005; Gallego and Uriag-

${ }^{22}$ In fact, Gallego and Uriagiereka (2007) offer the distinction into $\mathrm{C}_{\mathrm{COMP}} / \mathrm{C}_{\mathrm{DEF}(\text { ective), }}$, the latter present in SUBJ. $\mathrm{C}_{\mathrm{DEF}}$ is immune to PIC (thus enabling high long-distance connectivity effects) and manifests weak left-peripheral activity. 
iereka 2007, among others), it is clear that there must be a featural relation between the matrix controller and the embedded verb. Such a relation seems unattainable within Zwart's FLEXIBLE account. ${ }^{23}$

Let us further consider the limited availability of FOC/TOP/wh-driven movements in embedded IND/SUBJ clauses in terms of their phrasal architecture. On a purely descriptive level, (36-38) could be taken to support Thráinsson's LDH proposals concerning the distribution of functional projections in the left periphery of a given language. In order to account for their constrained occurrence in Spanish SUBJ constructions, it may be assumed that complementizer (phase) heads $\mathrm{C}$ indicative and $\mathrm{C}$ defective select from a different set of functional projections, in compliance with (42b).

\section{The Limited Diversity Hypothesis (LDH, Thráinsson 1996: 257)}

(b) The FCs selected by a given language may not be present in all clause types of a given language.

To conclude, the presence/absence of certain functional projections within the left periphery of a given construction appears at least to to some extent visible thorough the featural (morphosyntactic) composition of the LIs selected from the Numeration. This, in turn, allows to assume that in certain syntactic configurations, e.g. quantifier interaction in Polish or SUBJ in embedded clauses in Spanish, the computation establishes the dependencies long before any TP-internal conflicts arise.

\subsection{The nature of Merge-Erase (Escape)}

Let us now look in some more detail at how the FLEXIBLE computation along the lines of Zwart (2007) captures the essence of dislocation phenomena. Zwart (2007) proposes to replace the traditional understanding of Move/Internal Merge (Chomsky 2001) with Merge-Erase, whereby (as in the case of 28, repeated here as 43) "no movement takes place, but dat/welk boek is erased after another token of the same item is merged to the comment/ground domain".

\section{(a) topic}

$$
\begin{aligned}
& \text { Dat boek ken jij niet } \\
& \text { that book know:2SG.INV you not } \\
& \text { '[You] don't know this book.' }
\end{aligned}
$$

\footnotetext{
${ }^{23}$ According to the $P S i C L$ reviewer, this can be handled via a combination of local head-to-head relations. Such a combination would not avoid a massive look-ahead, though (see 41).
} 
(b) wh-phrase

$\begin{array}{lll}\text { Welk boek ken } & \text { jij niet } \\ \text { which book know:2SG.INV } & \text { you not } \\ \text { 'Which book don't you know?' } & & \end{array}$

The mechanism raises a number of legitimate questions, though. Consider first the socalled subjacency-alleviating effects, discussed in detail by Bošković (1995) and Richards (2001), as in (44).

(44) Subjacency-alleviating effects (Bošković 1995: 13-14)

(44a) $\mathrm{Kogo}_{\mathrm{i}} \mathrm{kakvo}_{\mathrm{j}}$ e pital Ivan $\mathrm{t}_{\mathrm{i}} \mathrm{t}_{\mathrm{j}}$ who-ACC.SG what-ACC.SG AUX ask-3SG.PAST Ivan 'Who did Ivan ask what?'

(44b) *Kakvo Kogo $_{i}$ e pital Ivan $t_{i} t_{j}$ what-ACC.SG who-ACC.SG AUX ask-3SG.PAST Ivan *'What did Ivan ask whom?'

(44c) Koj kogo $_{\mathrm{j}}$ kakvo $_{\mathrm{y}} \mathrm{t}_{\mathrm{i}}$ e pital $\mathrm{t}_{\mathrm{j}} \mathrm{t}_{\mathrm{y}}$ who-NOM.SG who-ACC.SG what-ACC.SG AUX ask-3SG.PAST 'Who asked whom what?'

(44d) Koji $k_{\mathrm{i}} \mathrm{kako}_{\mathrm{y}} \mathrm{kogo}_{\mathrm{j}} \mathrm{t}_{\mathrm{i}}$ e pital $\mathrm{t}_{\mathrm{j}} \mathrm{t}_{\mathrm{y}}$ who-NOM.SG what-ACC.SG who-ACC.SG AUX ask-3SG.PAST 'Who asked what whom?'

The fronting of interacting wh-elements in (44a) obeys Subjacency/Attract-Shortest. Yet, in $(44 \mathrm{c}-\mathrm{d})$, the rule is obviated due to the introduction of yet another wh- and its subsequent raising prompted by a higher attractor. Richards's (2001) account of the said interaction is given as (45).

Principle of Minimal Compliance (Richards (2001: 199)

If the tree contains a dependency headed by $\mathrm{H}$ which obeys constraint $\mathrm{C}$, any syntactic object $\mathrm{G}$ which $\mathrm{H}$ immediately c-commands can be ignored for purposes of determining whether $\mathrm{C}$ is obeyed by other dependencies.

Satisfying the wh-feature of $\mathrm{C}$ at a sufficiently early stage renders the other two whelements equidistant from the attractor, i.e. immune to Subjacency (hence the optional ordering in $(44 c-d)$, reflected in $(46 c-d)$. 

(a) $[\alpha \beta \mathbf{C} \alpha \beta]$
(b) $*[\beta \alpha \mathbf{C} \alpha \beta]$
(c) $[\alpha \beta \gamma \mathbf{C} \gamma \alpha \beta]$
(d) $[\beta \alpha \gamma \mathbf{C} \gamma \alpha \beta]$

It seems that an adequate account of the trajectory of wh-movement stems from the analysis of the Attractor-Attractee relations expressible in terms of extraction vs. movement sites, crossing vs. nesting paths, etc. These, in turn, have no legitimate standing within a non-cartographic approach based solely on Escape (i.e. Merge-Erase).

In a similar vein, a TOP/FOC-extraction driven computation has little potential to prevent overgeneration as in (47), a case of extraction out of adjunct islands.

(a) *Which bike $\mathrm{FOC}_{\mathrm{FO}}$ can you make the claim [that Bill stole t]?

(b) *What ${ }_{\mathrm{FOC}}$ did John let the cat [before he opened t]?

(c) You can make the claim that Bill stole which bike?

(d) John let the cat before he opened what?

At this point, the derivation needs to specify Ground. For example, it can be the smallest TP in which the FOC-marked element is trapped. In that case, contrary to judgments, Escape would naturally force eviction of the wh-from the TP (48a), while still leaving it within the adjunct (48b), rendering the structure ungrammatical in case of further dislocation (48c).

(48) (a) $(*) \ldots[$ [сP before $[\mathrm{XP}$ e $[\mathrm{TP}$ he opened what $]$

(b) (?)... [CP before [XP what ${ }_{\mathrm{FOC}}[\mathrm{TP}$ he opened $\mathrm{t}]$

(b') (?)... [XP what ${ }_{\mathrm{FOC}}[\mathrm{TP}$ he opened $\mathrm{t}]$

(c) $\left(^{*}\right)\left[{ }_{\mathrm{CP}}\right.$ what $_{\mathrm{FOCi}} \ldots\left[\mathrm{CP}\right.$ before $\left[\mathrm{XP} \mathrm{t}_{\mathrm{i}}\left[\mathrm{TP}\right.\right.$ he opened $\left.\left.\left.\left.\mathrm{t}_{\mathrm{i}}\right]\right]\right]\right]$

Notice that on strict application of Escape, there is nothing that prevents wh-movement in $\left(59 b^{\prime}\right)$, i.e. before the XP turns into an adjunct-island. Unless some other Escapevoiding factors are considered, the FLEXIBLE approach proves inefficient in handling the problems exemplified above. On the other hand though, the introduction of such factors would effectively place it in the same league with various optimality-based accounts, resulting in something like (49).

(49) (C1) Adjunct island >> (C2) Escape

\begin{tabular}{|l|c|c|}
\hline & Adjunct island & Escape \\
\hline$(47 \mathrm{c})$ & $* !$ & \\
\hline$(47 \mathrm{a}) \odot$ & & $*$ \\
\hline
\end{tabular}


In the discussion presented so far, it has been tacitly assumed that wh-fronting is invariably "Focus-extraction" driven (see 30). At this point let us explore other possibilities. Consider some of the exceptions to multiple wh-movement in multiple wh-fronting (MWF) languages like Serbo-Croatian, Polish or Russian (Bošković 2002: 360-365):

(50) Serbo-Croatian (Bošković’s 26-27)

(50a) Ko je kupio koju knigu? who is bought which book 'Who bought which book?'

(50b) ?Ko je koju knigu kupio? Who is which book bought 'Who bought which book?

The reason for which the speakers of Serbo-Croatian consider (50b) slightly degraded might stem from the fact that which book is D-linked, i.e. its reference is discoursegiven. In Bulgarian and Polish the option seems allowed (see 52 and 53), yet, interestingly, given a sequence of two fronted wh-phrases in Bulgarian split with a parenthetical, only the one with the D-linked wh-phrase following the parenthetical converges.

(51) Bulgarian (Bošković's 30-31)

(51a) $\quad ? *$ Koj, spored tebe, kakvo e kupil? who according to you what is bought

'Who, according to you, bought what?'

(50b) ?Koj, spored tebe, koja kniga e kupil? who according to you which book is bought 'Who, according to you, bought which book?'

In order to account for the specificity of D-linked wh-dislocation, Bošković (2002: 364) distinguishes between wh-movement, pure focus movement and scrambling, claiming that "the second way is the only one that is always fully acceptable for all speakers of (MWF) languages". However, the account falls short of explaining the movement in (52), quoted after Grebenyova (2006), as well as in (53) should be optional:

Russian

(52a) Kakomu studentu kakuju knigu Ivan podaril? which student which book Ivan gave 'Which student did Ivan give which book?' 
(52b) Kakomu studentu Ivan podarli kakuju knigu?

which student Ivan gave which book

'Which student did Ivan give which book?'

(53) Polish

(53a) Któremu studentowi którą książkę Ivan podarował?

which student which book Ivan gave

'Which student did Ivan give which book?'

(53b) Któremu studentowi Iwan podarował którą książkę?

which student Ivan gave which book

'Which student did Ivan give which book?'

Alternatively, it would be natural to assume that non-D-linked and D-linked wh-phrases end up in different structural positions. Given the general definitions of Focus (new information) and Topic (old/given information), it is plausible to expect the two to move for different reasons: whereas the former instantiate FOC-driven movement, the latter are TOP-triggered (thus moving to TopP). Such a proposal is supported by Boeckx and Grohmann (2004), who offer a scrambling-based analysis of the optionality of D-linked wh-fronting. The Escape system offers little if any account of the diversified motivation for wh-movement.

The data presented above are difficult to explain within a non-cartographic approach to syntax postulating wh-movement solely as externalization of offending elements. On the observational level, the seemingly simple, dynamic mechanism offered within the FLEXIBLE account is obscured by the fact that the wh-fronting may not have a unanimous nature, it may apparently be triggered by different factors. This, in turn, naturally calls for differentiated landing sites, i.e. functional projections hosting dislocated elements. The evidence from Spanish and Polish suggests that these landing sites may indeed be assumed to come in fixed configurations. At this point then, the distinction between a (supposedly) non-cartographic computation and the one based on Thráinsson's (1996) LDH becomes vacuous.

\section{Conclusions}

The aim of this paper was three-fold. Primarily, it was supposed to show that Zwart's Escape system shares a number of mutual characteristics with the strongly derivational approaches postulated by, among others, Frampton and Gutmann (2002), Epstein and Seely (2002) and Collins (2002). In that respect, it depicted some non-trivial computational problems encountered by these theories, i.e. questionable handling of linearization procedures. Next, the argumentation focused almost exclusively on Zwart's 
FLEXIBLE account and its non-cartographic postulates. The discussion revealed a number of potentially puzzling issues that such a theory would have to address. Finally, an alternative analysis of the presented data was offered on which the empirical facts were taken to support a moderately cartographic view of the sentence structure as presented by Thráinsson's (1996) Limited Diversity Hypothesis.

\section{REFERENCES}

Abraham, W., S. Epstein, H. Thráinsson and J. Zwart (eds.). 1996. Minimal ideas: Syntactic studies in the minimalist framework. Amsterdam: John Benjamins Publishers.

Adger, D., C. de Cat and G. Tsoulas (eds.). 2004. Peripheries: syntactic edges and their effects. Dordrecht: Kluwer.

Baker, M. 1985. “The Mirror Principle and morphosyntactic explanation”. Linguistic Inquiry 16. 373-416.

Bateman, L. and C. Ussery (eds.). 2005. Proceedings of the 35th meeting of the Northeast Linguistics Society. University of Connecticut, Storrs.

Barrie, M. 2005. "On unifying antisymmetry and Bare Phrase Structure”. In Bateman, L. and C. Ussery (eds.). 103-114.

Boeckx, C. and K. Grohmann. 2004. "Sub-move: Towards a unified account of scrambling and D- Linking”. In Adger, D. et al. (eds.). 341-357.

Bobaljik, J.D. 1999. "Adverbs: the hierarchy paradox". Glot International 4. 27-28.

Bošković, Ž. 1995a. On certain violations of the superiority condition, AgrO, and economy of derivation. [Ms., University of Connecticut.]

Bošković, Ž. 1995b. Superiority effects with multiple wh-fronting in Serbo-Croatian. [Ms., University of Connecticut.]

Bošković, Ž, 2002. “On multiple wh-fronting”. Linguistic Inquiry 33. 351-383.

Cegłowski, P. 2006. Why move? The analysis of the representational and derivational approaches to English syntax. [Unpublished PhD dissertation, Adam Mickiewicz University, Poznań.]

Cegłowski, P. 2007. "Floating inflection reanalyzed - Morphological evidence for T-C movement in Polish". Paper read at PASE conference, Szczyrk, Poland.

Chomsky, N. 1986. Barriers. Cambridge, MA: MIT Press.

Chomsky, N. 1994. Bare Phrase Structure. (MIT Occasional Papers in Linguistics 5.)

Chomsky, N. 1995. The Minimalist Program. Cambridge, MA: MIT Press.

Chomsky, N. 1998/2000. “Minimalist inquiries: The framework”. In Martin, R. et al. (eds.). 89156.

Chomsky, N. 1999. Derivation by Phase. (MIT Occasional Papers in Linguistics 18.)

Chomsky, N. 2001. Beyond explanatory adequacy. [Ms., Massachusetts Institute of Technology.]

Chomsky, N. 2005. On phases. [Ms., Massachusetts Institute of Technology.]

Cinque, G. 1999. Adverbs and functional heads: A crosslinguistic perspective. New York: Oxford University Press.

Collins, C. 2002. "Label-Free Syntax”. In Epstein S. and D. Seely (eds.). 42-61.

Collins, C. and H. Ura. 2001. Accessibility. [Ms., Cornell University and Kwansei Gakuin University.] 
Den Besten, H. 1977. On the interaction of root transformations and lexical deletive rules. [Ms., Massachusetts Institute of Technology and University of Amsterdam.]

Den Besten, H. 1989. Studies in West-Germanic syntax. [Unpublished PhD dissertation, University of Tilburg.]

Dziubalska-Kołaczyk, K. (ed.). 2006. IFAtuation: A life in IFA. A Festschrift for professor Jacek Fisiak on the occasion of his 70th birthday. Poznań: Wydawnictwo Naukowe UAM.

Epstein, S. and D. Seely. 2002. "Rule applications as cycles in a level-free syntax". In Epstein S. and D. Seely (eds.). 65-84.

Epstein, S. and D. Seely (eds.). 2002. Derivation and explanation in the Minimalist Program. Oxford: Blackwell Publishers.

Frampton, J. and S. Gutmann. 2002. "Crash-proof syntax”. In Epstein S. and D. Seely (eds.). 90103.

Gallego, A. and J. Uriagereka. 2007. "Defective C". Paper presented at the 2nd Brussels Conference on Generative Linguistics Alternatives to Cartography, Catholic University of Brussels.

Grebenyova, L. 2006. "When multiple wh-fronting is not multiple". Paper presented at the 1st Annual Meeting of Slavic Linguistic Society, Indiana University, Bloomington, IN.

Haegeman, L. (ed.). 1997. Elements of grammar: Handbook of generative syntax. Dordrecht: Kluwer Academic Publishers.

Hornstein, N. 1999. "Movement and control". Linguistic Inquiry 30. 69-96.

Jaspers, D. 1998. "Categories and recursion". Interface 12. 81-112.

Kayne, R. 1994. The antisymmetry of syntax. Cambridge, MA: MIT Press.

Kenstowicz, M. 2001. Ken Hale: A life in language. Cambridge, MA: MIT Press.

Martin, R., D. Michaels and J. Uriagereka (eds.). 2000. Step by step: Essays in honour of Howard Lasnik. Cambridge, MA: MIT Press.

Matushansky, O. 2006. "Head-movement in linguistic theory". Linguistic Inquiry 37. 69-109.

Müller, S. (ed.) 2005. Proceedings of the HPSG05 Conference. Department of Informatics, University of Lisbon: CSLI Publications.

Myusken, P. 1982. "Parametrizing the notion Head". Journal of Linguistic Research 2. 57-75.

Neeleman, A. and H. van de Koot. 2007. The nature of discourse templates. [Ms., University College London.]

Nilsen, Ø. 2003. Eliminating positions: syntax and semantics of sentential modification. [Unpublished $\mathrm{PhD}$ dissertation, Utrecht University.]

Pesetsky, D. and E. Torrego. 2001. "T-C movement: Causes and consequences”. In Kenstowicz, M. (ed.). 355-426.

Richards, N. 2001. Movement in language. Interactions and architectures. New York: Oxford University Press.

Rizzi, L. 1997. "The fine structure of the left periphery". In: Haegeman, L. (ed.). 281-337.

Rizzi, L. 2004. On the cartography of syntactic structures. In: Rizzi (ed.). 3-16.

Rizzi, L. (ed.). 2004. The structure of CP and IP: The cartography of syntactic structures, Volume 2. Oxford University Press: Oxford.

Tajsner, P. and P. Cegłowski. 2006. "Topicalisation and object fronting in Polish: A view from a minimalist perspective". In Dziubalska-Kołaczyk, K. (ed.). 99-131.

Thráinsson, H. 1996. "On the (non-)universality of functional categories". In Abraham, W. et al. (eds.). 253-281.

Torrego, E. and J. Uriagereka. 1992. Indicative dependents. [Ms., University of Massachusetts, Boston].

Van Craenenbroeck, J. 2006. "Transitivity failures in the left periphery and foot-driven movement operations". In Weijer, J. van de and L. Bettelou (eds.). 52-64. 
Weijer, J. van de and L. Bettelou (eds.). 2006. Linguistics in the Netherlands 23(1). Amsterdam: John Benjamins.

Zwart, J.W. 2007. "Uncharted territory? Towards a noncartographic account of Germanic syntax". Groninger Arbeiten zur germanistischen Linguistik 45. 55-75.

Zwart, J.W. and J. Fortuny. 2008. "Deriving the LCA". Paper presented at the Theoretical Linguistics in the Netherlands (TIN-dag) conference, Utrecht. 